\title{
EVALUATING ELASTIC-PLASTIC BEHAVIOUR OF ROCK MATERIALS USING HOEK-BROWN FAILURE CRITERION
}

\author{
Hadi Hasanzadehshooiili ${ }^{1}$, Ali Lakirouhani ${ }^{2}$, Jurgis Medzvieckas ${ }^{3}$ \\ ${ }^{1,2}$ Department of Civil Engineering, University of Zanjan, Zanjan, Iran \\ ${ }^{3}$ Faculty of Civil Engineering, Vilnius Gediminas Technical University, \\ Saulètekio al. 11, LT-10223 Vilnius, Lithuania \\ E-mails: ${ }^{1}$ h.hasanzadeh.shooiili@gmail.com; ${ }^{2}$ rou001@znu.ac.ir; ${ }^{3}$ jurgism@vgtu.lt (corresponding author) \\ Received 10 Jan. 2012; accepted 23 Apr. 2012
}

\begin{abstract}
As a matter of fact, the failure criteria only predict failure's initiation in materials. And, in order to predict postyield behaviour of materials, a much complicated formulation for stress-strain relationship is required, which we know as plasticity theory. For instance, these formulations are developed based on Mohr-Coulomb criterion for soils and DruckerPrager criterion for concrete. According to a majority of rock mechanics researchers, the empirical and experimental Hoek-Brown failure criterion is one of the well-progressed and suitable criteria, which can efficiently predict the rock failure initiation under different stress states for various types of intact rocks and rock masses. In this article, according to the suggestion by Heok explained in his paper of 1997, this rugged mentioned criterion is considered as a yield criterion and the elastic-perfect plastic behaviour of rock masses is determined using calculating material constitutive matrix's arrays in terms of Hoek-Brown's material constants and mechanical characteristics of rock materials in the general stress space, considering associated flow rule.
\end{abstract}

Keywords: Hoek-Brown failure criterion, elastic-plastic materials, associated flow rule, limited strain.

\section{Introduction}

According to material type, application and conditions, which are supposed to be forced to materials, failure criteria can be categorized into 3 major groups: theoretical criteria, empirical criteria and a mixed form of two mentioned groups, theoretical-empirical criteria (Lakirouhani, Hasanzadehshooiili 2011).

Also, to truly choose a criterion which efficiently describes material's behaviour, some important aspects should be considered; such as its accuracy and applicability. Also, this criterion should include a wide range of desired material types and its parameters should be accessible for different material's types (Lakirouhani, Hasanzadehshooiili 2011).

As we know, in case of majority of materials, various criteria are introduced and widely used to predict failure's initiation and to evaluate elastic, plastic and post-yielding behaviour of materials (Kargaudas, Adamukaitis 2010; Petkevičius, Valivonis 2010; Dhadwal, Kudtarkar 2010). For instance, Plane Griffith crack theory is one of theoretical criterion, which considers tension as the main important reason of crack initiation; and a variety of empirically developed criteria are available for predicting failure initiation (Lakirouhani, Hasanzadehshooiili 2011). Also, plastic behaviour of concrete is determined using Drucker-Prager criterion based on plasticity theory (Nayak, Zienkiewicz 1972; Ortiz 1985; Siriwardane, Desai 1983; Hjiaj et al. 2002; Jeremić, Yang
2002; Desai 1980). In case of soils, some of available formulations are developed based on Mohr-Coulomb criterion (Nayak, Zienkiewicz 1972; Runesson 1987; Desai 1980).

According to the opinion of rock mechanics specialists, Hoek-Brown failure criterion, which is developed experimentally and empirically (Hoek, Brown 1980), is the most applied and useful criterion that can be used efficiently and economically to predict rock's failure initiation. This failure criterion includes all of the described requirements for a good failure criterion, such as: accuracy, including a wide range of rock materials from intact rock to rock masses, availability of its parameters for different rock types, and etc.

There is a broad range of studies on rock materials (Bizjak 2003; Petje et al. 2006; Macuh, Žlender 2007; Petkovšek et al. 2010). To accurately model the real behaviour of rock materials, lots of efforts are based on this rugged-mentioned criterion, Hoek-Brown criterion (Wan 1992; Serrano et al. 2005; Merifield et al. 2006). Some studies are based on the 1997 version (Hoek, Brown 1997) of Hoek-Brown criterion (Wan 1992). Meanwhile, some of other studies include analytical or approximate solutions for Hoek-Brown media and are model-based studies, which have been carried out on some special geometry, like circular openings (Sharan 2005; Park, Kim 2006). In this paper, according to Hoek and Brown's suggestion (Hoek, Brown 1997), assuming it as a yield criterion, in order to evaluate post-yielding behaviour of 
rock materials using generalized Hoek-Brown criterion (Hoek et al. 2002), the components of elastic-plastic constitutive matrix of material are assessed using this criterion, based on plasticity theory and associated flow rule.

To do this, defining the probable failure plane, calculations of failure criterion in terms of local stresses in failure plane and its derivatives are presented.

\section{Hoek-Brown failure criterion}

Hoek-Brown failure criterion is properly developed under the aegis of Hoek and Brown's experimental works from 1980 to 2002. And its last version was presented in 2002, considering rock disturbance factor, $\mathrm{D}$, and considerably much more developed specifications and constants (Hoek, Brown 1980):

$$
\sigma_{1}=\sigma_{3}+\sigma_{c i}\left(m_{b} \frac{\sigma_{3}}{\sigma_{c i}}+s\right)^{a},
$$

where: $\sigma_{1}$ and $\sigma_{3}$, are maximum and minimum principle stresses in general stress space; $m_{b}$ is the HoekBrown constant for rock masses and $s$ and $a$, are constants which are determined considering rock mass specifications. And $\sigma_{c i}$ is uniaxial compressive strength of intact rock material (Hoek et al. 2002; Lakirouhani, Hasanzadehshooiili 2011).

$$
\begin{gathered}
m_{b}=m_{i} \exp \left(\frac{G S I-100}{28-14 D}\right) ; \\
s=\exp \left(\frac{G S I-100}{9-3 D}\right) ; \\
a=1 / 2+1 / 6\left(e^{-G S I / 15}-e^{-20 / 3}\right) .
\end{gathered}
$$

\section{Plastic behaviour}

As a matter of fact, Hooke's law is applied to predict mechanical behaviour of materials in the elastic state (Sadrnejad 2004). Nevertheless, after yielding and plastic strain initiation, this formulation will be led to an over estimated prediction. Thus, in order to achieve correct plastic behaviour of materials, the correct relationship between stress and strain should be calculated using plasticity theory after yielding.

In general, strain tensor is composed of elastic and plastic strain tensors (Jeremić, Yang 2002; Nayak, Zienkiewicz 1972; Zergua, Naimi 2006):

$$
\begin{aligned}
& \underset{\approx}{\varepsilon}=\underset{\approx}{\varepsilon}+\underset{\approx}{\varepsilon} ; \\
& \sigma=\underline{D}^{e} \varepsilon^{e} .
\end{aligned}
$$

But, after yielding, considering Eq. (7), which is developed for associated flow rule (Siriwardane, Desai 1983; Jeremić, Yang 2002; Desai 1980; Nayak, Zienkiewicz 1972; de Souza Neto et al. 2008):

$$
\underset{\approx}{\varepsilon^{p}}=\lambda \underset{\approx \sigma}{\partial \sigma} .
$$

The associated flow-rule, Eq. (7), is related to the plastic strain increment vector normal to the yield surface called normality rule. The normality rule has been confirmed for metals. And, for many soils and rocks, it overestimates the plastic deformations. For these materials, non-associative flow-rule is more suitable. The concept of stable and unstable material defines the type of materials for which the associated flow-rule can be applied. The stress-strain curve in Fig. 2 is typical for a strain hardening material and is stable for this approach. For this material, associated flow-rule can be used. A strain softening material illustrated in Fig. 3 is unstable for associated flow-rule. Since many soils and rocks correspond to this behaviour, in order to use the associated flow rule for soils and rocks, strains must be bounded until the strain hardening process goes. Thus, the associated flow-rule can be used by limiting the strain to the $\varepsilon_{u}$ shown in

Fig. 3. The limiting value, $\varepsilon_{u}$, is presented in Eq. (8):

$$
\varepsilon=\varepsilon^{e}+\varepsilon^{p} \leq \varepsilon u
$$

Stress tensor can be calculated using the following equation:

$$
\underset{\approx}{\sigma}=\underline{D}^{e}\left(\underset{\approx}{\varepsilon-\varepsilon^{p}}\right)=\underline{D}_{\approx}^{e} \underset{\approx}{\varepsilon} \underline{D}^{e} \lambda \underset{\approx}{\frac{\partial F}{\partial \sigma}},
$$

where $\lambda, \underset{\approx}{\sigma}$ and $\underset{\approx}{\varepsilon}$ are plastic multiplier, stress tensor and strain tensor, also, $\underline{D}^{e}, \underset{\approx}{\varepsilon^{e}}$ and $\underset{\approx}{\varepsilon^{p}}$, represent elasticity matrix of material, elastic strain tensor and plastic strain tensor, respectively. " $\approx$ " and " " declare the indexes regarding tensor and matrix state, respectively.

Regarding perfect plastic theory and associated flow rule, the formula for $\lambda$ is presented in Eq. (10) (Own, Hinton 1980; de Souza Neto et al. 2008):

$$
\lambda=\frac{(\partial F / \partial \sigma)^{T} \underline{D}^{e} d_{\varepsilon}}{(\partial F / \partial \sigma)^{T} \underline{D}^{e}(\partial F / \partial \sigma)} .
$$

Stress-strain relationship is assessed using $\underline{D}^{e p}$, the formula of which is presented in Eq. (11) (de Souza Neto et al. 2008):

$$
\sigma \approx\left[\underline{D}^{e}-\frac{\underline{D}^{e}\left(\begin{array}{c}
\left.\frac{\partial F}{\partial \sigma}\right)\left(\frac{\partial F}{\partial \sigma}\right)^{T} \\
\approx
\end{array} \underline{D}^{e}\right.}{\left(\begin{array}{c}
\left.\frac{\partial F}{\partial \sigma}\right)^{T} \\
\approx
\end{array} \underline{D}^{e}\left(\begin{array}{c}
\frac{\partial F}{\partial \sigma} \\
\approx
\end{array}\right)\right.}\right] \underset{\approx}{\approx}=\underline{D}^{e p} \underset{\approx}{\varepsilon} .
$$




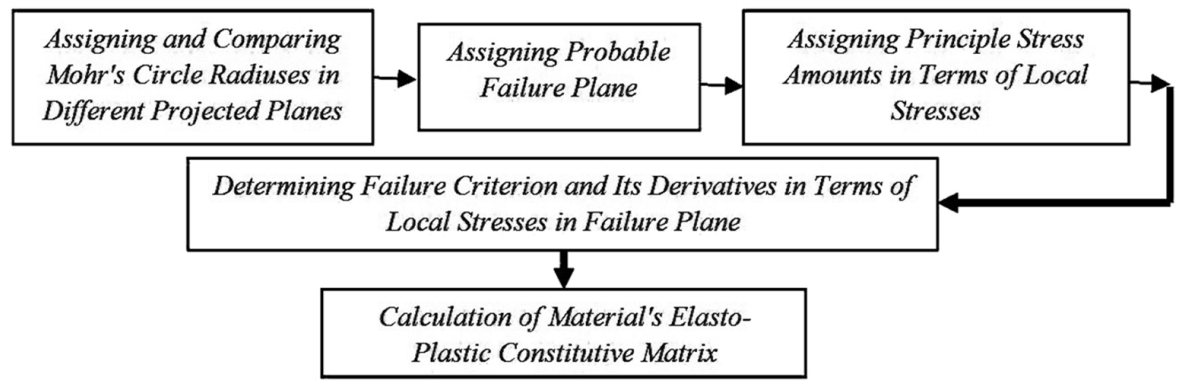

Fig. 1. Procedure for calculating the elastic-plastic matrix

In Fig. 1, the procedure for calculating elasticplastic matrix is presented.

\section{Using Hoek-Brown failure criterion for evaluating plastic behaviour of rock material}

In this section, material's elastic-plastic constitutive matrix is calculated, based on Hoek-Brown failure criterion, which is assumed as a yield criterion, considering perfect plastic materials and associated flow-rule.

\subsection{Comparing Mohr's Circle radiuses in different planes and assigning probable failure plane, in order to assign principle stress amounts in terms of local stresses}

Because of Hoek-Brown failure criterion's development in principle space, in order to gain a simplified efficient specification of this criterion in general stress space, the criterion is projected to the $\mathrm{xy}, \mathrm{yz}$ and $\mathrm{xz}$ planes, separately. Then, in order to assign probable failure plane and principle stress amounts in terms of local stresses, $R_{\max 1}$, $R_{\max 2}$ and $R_{\max 3}$, which are Mohr's circle radiuses in $x y$, $\mathrm{xz}$ and $\mathrm{yz}$ planes, respectively, should be calculated and compared.

The largest Mohr's circle radius in amount in projection planes declares yield plane. And all of the calculations must be done in this plane:

$$
\begin{aligned}
& R_{\max 1}=\sqrt{\left(\frac{\sigma_{x}-\sigma_{y}}{2}\right)^{2}+\sigma_{x y}^{2}} ; \\
& R_{\max 2}=\sqrt{\left(\frac{\sigma_{x}-\sigma_{z}}{2}\right)^{2}+\sigma_{x z}^{2}} ; \\
& R_{\max 3}=\sqrt{\left(\frac{\sigma_{y}-\sigma_{z}}{2}\right)^{2}+\sigma_{y z}^{2}} .
\end{aligned}
$$

State I: if $R_{\max 1} \succ\left(R_{\max 2}, R_{\max 3}\right)$, then:

$$
\sigma_{1}=\left(\frac{\sigma_{x}+\sigma_{y}}{2}\right)+\sqrt{\left(\frac{\sigma_{x}-\sigma_{y}}{2}\right)^{2}+\sigma_{x y}^{2}} ;
$$

$$
\sigma_{3}=\left(\frac{\sigma_{x}+\sigma_{y}}{2}\right)-\sqrt{\left(\frac{\sigma_{x}-\sigma_{y}}{2}\right)^{2}+\sigma_{x y}^{2}} .
$$

State II : if $R_{\max 2} \succ\left(R_{\max 1}, R_{\max 3}\right)$, then:

$$
\begin{aligned}
& \sigma_{1}=\left(\frac{\sigma_{x}+\sigma_{z}}{2}\right)+\sqrt{\left(\frac{\sigma_{x}-\sigma_{z}}{2}\right)^{2}+\sigma_{x z}^{2}} ; \\
& \sigma_{3}=\left(\frac{\sigma_{x}+\sigma_{z}}{2}\right)-\sqrt{\left(\frac{\sigma_{x}-\sigma_{z}}{2}\right)^{2}+\sigma_{x z}^{2}} .
\end{aligned}
$$

State III : if $R_{\max 3} \succ\left(R_{\max 1}, R_{\max 2}\right)$, then:

$$
\begin{aligned}
& \sigma_{1}=\left(\frac{\sigma_{y}+\sigma_{z}}{2}\right)+\sqrt{\left(\frac{\sigma_{y}-\sigma_{z}}{2}\right)^{2}+\sigma_{y z}^{2}} ; \\
& \sigma_{3}=\left(\frac{\sigma_{y}+\sigma_{z}}{2}\right)-\sqrt{\left(\frac{\sigma_{y}-\sigma_{z}}{2}\right)^{2}+\sigma_{y z}^{2}} .
\end{aligned}
$$

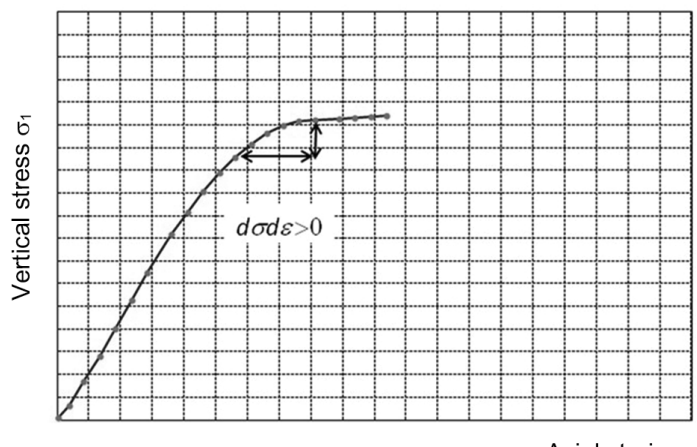

Axial strain $\varepsilon_{1}$

Fig. 2. Stable stress-strain curve

According to these 3 mentioned states, regarding loading conditions and planes, principle stresses can be located in each one of these states.

Because of similarities in calculation procedure in 2 other states, formulation is developed only in xy plane. And the procedure in $\mathrm{xz}$ and $\mathrm{yz}$ planes is completely similar to the following methodology.

At first, Hoek-Brown failure criterion should be declared in terms of general local stresses. 


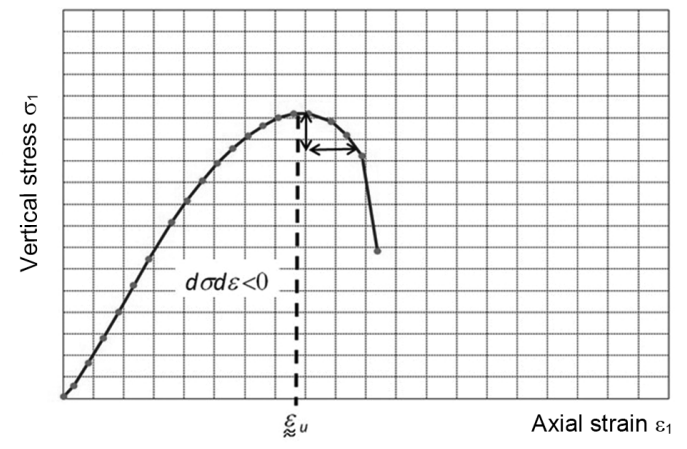

Fig. 3. Unstable stress-strain curve

According to Eq. (1), $\sigma_{1}=\sigma_{3}+\sigma_{c i}\left(m_{b} \frac{\sigma_{3}}{\sigma_{c i}}+s\right)^{a}$, thus, the yield surface will be:

$$
F=\sigma_{1}-\sigma_{3}-\sigma_{c i}\left(m_{b} \frac{\sigma_{3}}{\sigma_{c i}}+s\right)^{a}=0 .
$$

Assuming that compressive stresses are negative and tensile stresses are positive, regarding the algebraic signs, $\sigma_{1}$ and $\sigma_{3}$ will be minimum and maximum principle stresses, respectively. Thus the yield surface will change into Eq. (22):

$$
F=\sigma_{1}-\sigma_{3}-\sigma_{c i}\left(-m_{b} \frac{\sigma_{1}}{\sigma_{c i}}+s\right)^{a}=0
$$

\subsection{Determining failure criterion and its derivatives in terms of local stresses in failure plane}

With substitution of mentioned values for principle stresses in Eqs (15) and (16), into yield surface, in Eq. (22), the yield criterion will be changed into Eq. (23):

$$
\begin{aligned}
& F=2 \sqrt{\left(\frac{\sigma_{x}-\sigma_{y}}{2}\right)^{2}+\sigma_{x y}^{2}}-\sigma_{c i} \cdot \\
& {\left[\left(-\frac{m_{b}}{\sigma_{c i}}\right)\left(\left(\frac{\sigma_{x}+\sigma_{y}}{2}\right)+\sqrt{\left(\frac{\sigma_{x}-\sigma_{y}}{2}\right)^{2}+\sigma_{x y}^{2}}\right)+S\right]^{a}=0,}
\end{aligned}
$$

thus:

$$
\frac{\partial F}{\partial \sigma}=\left\{\begin{array}{c}
\frac{\partial F}{\partial \sigma_{x}} \\
\frac{\partial F}{\partial \sigma_{y}} \\
\frac{\partial F}{\partial \sigma_{z}} \\
\frac{\partial F}{\partial \sigma_{x y}} \\
\frac{\partial F}{\partial \sigma_{y z}} \\
\frac{\partial F}{\partial \sigma_{x z}}
\end{array}\right\}=\left\{\begin{array}{c}
\frac{\partial F}{\partial \sigma_{x}} \\
\frac{\partial F}{\partial \sigma_{y}} \\
0 \\
\frac{\partial F}{\partial \sigma_{x y}} \\
0 \\
0
\end{array}\right\}
$$

in which:

$$
\begin{gathered}
\frac{\partial F}{\partial \sigma_{x}}=\frac{1}{2} d F d x_{11}+a_{m b} \cdot\left(\frac{1}{2}+\frac{1}{4} d F d x_{11}\right) \cdot d F d x_{12}{ }^{a-1} \\
\frac{\partial F}{\partial \sigma_{y}}=-\frac{1}{2} d F d x_{11}+a_{m b} \cdot\left(\frac{1}{2}-\frac{1}{4} d F d x_{11}\right) \cdot d F d x_{12}{ }^{a-1} \\
\frac{\partial F}{\partial \sigma_{x y}}=\frac{\sigma_{x y}}{R_{\max 1}}\left[2+a_{m b}\left(d F d x_{12}\right)^{a-1}\right] \\
\frac{\partial F}{\partial \sigma_{z}}=\frac{\partial F}{\partial \sigma_{y z}}=\frac{\partial F}{\partial \sigma_{x z}}=0
\end{gathered}
$$

In Eqs (25)-(28), $\mathrm{dFdx}_{11}$ and $\mathrm{dFdx}_{12}$ are local parameters that are assumed to simplify calculation procedure and are attained from the following equations:

$$
d F d x_{11}=\frac{\sigma_{x}-\sigma_{y}}{R_{\max }}
$$

$$
\begin{aligned}
d F d x_{12} & =\frac{-m_{b} \sigma_{1}}{\sigma_{c i}}+s= \\
& {\left[\left(\frac{-m_{b}}{\sigma_{c i}}\right)\right.} \\
& \left.\cdot\left(\left(\frac{\sigma_{x}+\sigma_{y}}{2}\right)+\sqrt{\left(\frac{\sigma_{x}-\sigma_{y}}{2}\right)^{2}+\sigma_{x y}^{2}}\right)+s\right] .
\end{aligned}
$$

\subsection{Calculation of material's elastic-plastic constitutive matrix}

At first, elastic behaviour of materials is achieved from material elasticity matrix mentioned in Eq. (31):

$$
\begin{aligned}
\underline{D}^{e} & =\frac{E}{(1+v)(1-2 v)} \cdot \\
& {\left[\begin{array}{cccccc}
1-v & v & v & 0 & 0 & 0 \\
v & 1-v & v & 0 & 0 & 0 \\
v & v & 1-v & 0 & 0 & 0 \\
0 & 0 & 0 & \frac{1-2 v}{2} & 0 & 0 \\
0 & 0 & 0 & 0 & \frac{1-2 v}{2} & 0 \\
0 & 0 & 0 & 0 & 0 & \frac{1-2 v}{2}
\end{array}\right] . }
\end{aligned}
$$

And then, material elastic-plastic constitutive matrix, based on Hoek-Brown criterion, considering yield surface derivatives and material elasticity matrix is presented in Eq. (32): 


$$
\begin{aligned}
\underline{D^{e p}} & =\frac{E}{(1+\cup)(1-2 \cup)} \cdot \\
& {\left[\begin{array}{lllllll}
D_{11} & D_{12} & D_{13} & D_{14} & D_{15} & D_{16} \\
D_{21} & D_{22} & D_{23} & D_{24} & D_{25} & D_{26} \\
D_{31} & D_{32} & D_{33} & D_{34} & D_{35} & D_{36} \\
D_{41} & D_{42} & D_{43} & D_{44} & D_{45} & D_{46} \\
D_{51} & D_{52} & D_{53} & D_{54} & D_{55} & D_{56} \\
D_{61} & D_{62} & D_{63} & D_{64} & D_{65} & D_{66}
\end{array}\right] \cdot ; }
\end{aligned}
$$

$$
\begin{aligned}
& D_{11}= \\
& \frac{B^{2}+1 / 2 C^{2}-2 v B^{2}-3 / 2 v C^{2}+v^{2} C^{2}}{A^{2}+B^{2}-v A^{2}-v B^{2}-v C^{2}+1 / 2 C^{2}+2 A B v} ; \\
& D_{12}=D_{21}= \\
& \frac{-v^{2} C^{2}+1 / 2 v C^{2}+2 v A B-A B}{A^{2}+B^{2}-v A^{2}-v B^{2}-v C^{2}+1 / 2 C^{2}+2 A B v} ;
\end{aligned}
$$$$
D_{13}=D_{31}=
$$$$
\frac{-2 v^{2} B^{2}-v^{2} C^{2}+v B^{2}+1 / 2 v C^{2}+2 v^{2} A B-v A B}{A^{2}+B^{2}-v A^{2}-v B^{2}-v C^{2}+1 / 2 C^{2}+2 A B v}
$$$$
D_{14}=D_{41}=
$$$$
\frac{3 / 2 v A C-1 / 2 v B C-1 / 2 A C-v^{2} A C+v^{2} B C}{A^{2}+B^{2}-v A^{2}-v B^{2}-v C^{2}+1 / 2 C^{2}+2 A B v} ;
$$$$
D_{22}=
$$$$
\frac{A^{2}+1 / 2 C^{2}-2 v A^{2}-3 / 2 v C^{2}+v^{2} C^{2}}{A^{2}+B^{2}-v A^{2}-v B^{2}-v C^{2}+1 / 2 C^{2}+2 A B v} ;
$$$$
D_{23}=D_{32}=
$$$$
\frac{-2 v^{2} A^{2}-v^{2} C^{2}+v A^{2}+1 / 2 v C^{2}+2 v^{2} A B-v A B}{A^{2}+B^{2}-v A^{2}-v B^{2}-v C^{2}+1 / 2 C^{2}+2 A B v}
$$$$
D_{24}=D_{42}=
$$$$
\frac{3 / 2 v B C-1 / 2 v A C-1 / 2 B C+v^{2} A C-v^{2} B C}{A^{2}+B^{2}-v A^{2}-v B^{2}-v C^{2}+1 / 2 C^{2}+2 A B v} ;
$$$$
D_{33}=
$$$$
\frac{A^{2}+B^{2}+1 / 2 C^{2}-2 v A^{2}-2 v B^{2}-3 / 2 v C^{2}+v^{2} C^{2}}{A^{2}+B^{2}-v A^{2}-v B^{2}-v C^{2}+1 / 2 C^{2}+2 A B v}+
$$$$
\frac{2 \mathrm{v} A B-4 \mathrm{v}^{2} A B}{A^{2}+B^{2}-\mathrm{v} A^{2}-\mathrm{v} B^{2}-\mathrm{v} C^{2}+1 / 2 C^{2}+2 A B \mathrm{v}} ;
$$$$
D_{34}=D_{43}=
$$$$
\frac{v^{2} A C+v^{2} B C-1 / 2 v A C-1 / 2 v B C}{A^{2}+B^{2}-v v^{2}-v B^{2}-v C^{2}+1 / 2 C^{2}+2 A B v} ;
$$

$$
\begin{aligned}
& D_{44}= \\
& \frac{v^{2} A^{2}+v^{2} B^{2}-3 / 2 v A^{2}-3 / 2 v B^{2}+1 / 2 A^{2}+1 / 2 B^{2}}{A^{2}+B^{2}-v A^{2}-v B^{2}-v C^{2}+1 / 2 C^{2}+2 A B v}+ \\
& \frac{+v A B-2 v^{2} A B}{A^{2}+B^{2}-v A^{2}-v B^{2}-v C^{2}+1 / 2 C^{2}+2 A B v} ; \\
& D_{55}=D_{66}=\frac{1-2 v}{2} ; \\
& D_{15}=D_{16}=D_{25}=D_{26}=D_{35}=D_{36}= \\
& D_{45}=D_{46}=D_{51}=D_{52}=D_{53}=D_{54}= \\
& D_{56}=D_{61}=D_{62}=D_{63}=D_{64}=D_{65}=0 .
\end{aligned}
$$

In which, A, B and C, in Eqs (33)-(42), are yield surface's partial derivatives regarding $\mathrm{x}, \mathrm{y}$ and $\mathrm{xy}$ variables, respectively:

$$
\begin{aligned}
& A=\frac{\partial F}{\partial \sigma_{x}}=\frac{1}{2} d F d x_{1}+a_{m_{b}}\left(\frac{1}{2}+\frac{1}{4} d F d x_{1}\right) d F d x_{2}{ }^{a-1} \\
& B=\frac{\partial F}{\partial \sigma_{y}}=-\frac{1}{2} d F d x_{1}+a_{m_{b}}\left(\frac{1}{2}-\frac{1}{4} d F d x_{1}\right) d F d x_{2}{ }^{a-1} \\
& C=\frac{\partial F}{\partial \sigma_{x y}}=\frac{\sigma_{x y}}{R_{\max 1}}\left[2+a_{m_{b}}\left(d F d x_{12}\right)^{a-1}\right]
\end{aligned}
$$

\section{Conclusion}

Generally, material's constitutive behaviour is evaluated using elastic-plastic formulation and based on various criteria. The yield criteria are opted for regarding the material's type and behaviour. In case of rock materials, both theoretical and experimental criteria are widely applied. But, according to the majority of rock mechanics specialists, the experimentally and empirically developed criteria are much more efficient means used for prediction of the triggering of failure. Furthermore, among all of the welldeveloped criteria, due to the applicability of this rugged mentioned criterion to a broad range of rock materials from intact rock to highly fractured rock mass and its accuracy, Hoek-Brown failure criterion is believed to be one of the best criteria. Moreover, according to Hoek's suggestion, this criterion can be considered as a yield criterion. Then, to assess rock materials' constitutive behaviour, firstly, the elastic behaviour of material has been presented based on Hooke's elastic theory. Thus, determining the most probable failure plane, its corresponding yield criterion and its derivatives, also, relying on elastic-perfect plastic formulation, plastic behaviour of rock materials is evaluated in general stress space using material's constitutive matrix. To develop these relationships and predict materials' behaviour, the associated flow-rule has been applied and then, the components of material constitutive matrix have been presented. 


\section{References}

Bizjak, K. F. 2003. Stability analysis of underground openings for extraction of natural stone, Geologija 46(1): 167-174. http://dx.doi.org/10.5474/geologija.2003.017

Desai, C. S. 1980. A general basis for yield, failure and potential functions in plasticity, International Journal for $\mathrm{Nu}$ merical and Analytical Methods in Geomechanics 4(4): 361-375. http://dx.doi.org/10.1002/nag.1610040406

de Souza Neto, E. A.; Peric, D.; Owen, D. R. J. 2008. Computational Methods for Plasticity: Theory and Applications. John Wiley and Sons, Ltd. 2008. 814 p.

Dhadwal, R.; Kudtarkar, S. K. 2010. Investigation of stationary solutions of viscoelastic melt spinning equations and stability with respect to increasing viscoelasticity, Mathematical Modelling and Analysis 15(3): 287-298. http://dx.doi.org/10.3846/1392-6292.2010.15.287-298

Hjiaj, M.; Fortin, J.; de Saxce, G. 2002. A complete stress update algorithm for the non-associated Drucker-Prager model including treatment of the apex, International Journal of Engineering Science 41(10): 1109-1143. http://dx.doi.org/10.1016/S0020-7225(02)00376-2

Hoek, E.; Brown, E. T. 1980. Empirical strength criterion for rock masses, Journal of the Geotechnical Engineering Division ASCE 106(9): 1013-1035.

Hoek, E.; Brown, E. T. 1997. Practical estimates of rock mass strength, International Journal of Rock Mechanics and Mining Sciences 34(8): 1165-1186. http://dx.doi.org/10.1016/S1365-1609(97)80069-X

Hoek, E.; Carranza-Torres, C.; Corkum, B. 2002. Hoek-Brown failure criterion - 2002 Edition, in Proc. of "Mining Innovation and Technology" (NARMS-TAC 2002), 10 July, 2002, Toronto, Canada, 267-273.

Jeremić, B.; Yang, Z. 2002. Template elastic-plastic computations in geomechanics, International Journal for Numerical and Analytical Methods in Geomechanics 26(14): 1407-1427. http://dx.doi.org/10.1002/nag.251

Kargaudas, V.; Adamukaitis, N. 2010. Plastic deformations of steel frame: statics and dynamics, Statybinés konstrukcijos ir technologijos [Engineering Structures and Technologies] 2(3): 101-105.

Lakirouhani, A.; Hasanzadehshooiili, H. 2011. Review of rock strength criteria, in Proc. of the $22^{\text {nd }}$ World Mining Congress \& Expo. Istanbul, Turkey, 2011, 473-482.

Macuh, B.; Žlender. 2007. The impact of mechanical properties of rock to the collision of rock piece, Geologija 50(1): 189-196. http://dx.doi.org/10.5474/geologija.2007.015

Merifield, R. S.; Lyamin, A. V.; Sloan, S. W. 2006. Limit analysis solutions for the bearing capacity of rock masses using the generalised Hoek-Brown criterion, International Journal of Rock Mechanics and Mining Sciences 43(6): 920-937. http://dx.doi.org/10.1016/j.ijrmms.2006.02.001
Nayak, G. C.; Zienkiewicz, O. C. 1972. Elasto-plastic stress analysis. A generalization for various contitutive relations including strain softening, International Journal for $\mathrm{Nu}$ merical Methods in Engineering 5(1): 113-135. http://dx.doi.org/10.1002/nme.1620050111

Ortiz, M. 1985. A constitutive theory for the inelastic behavior of concrete, Mechanics of Materials 4(1): 67-93. http://dx.doi.org/10.1016/0167-6636(85)90007-9

Owen, D. J. R.; Hinton, E. 1980. Finite Elements in Plasticity: Theory and Practice. Pineridge Press Limited, Swansea, UK. 594 p.

Park, K.-H.; Kim, Y.-J. 2006. Analytical solution for a circular opening in an elastic-brittle-plastic rock, International Journal of Rock Mechanics and Mining Sciences 43(4): 616-622. http://dx.doi.org/10.1016/j.ijrmms.2005.11.004

Petje, U.; Mikoš, M.; Majes, B. 2006. Motion of rock masses on slope, Geologija 49(2): 393-408. http://dx.doi.org/10.5474/geologija.2006.028

Petkevičius, M.; Valivonis, J. 2010. Analysis of deflections up to failure of composite steel fiber-reinforced concrete clabs, Statybines konstrukcijos ir technologijos [Engineering Structures and Technologies] 2(2): 57-65.

Petkovšek, A.; Maček, M.; Majes, B. 2010. A contribution to the better understanding of swelling in soils and soft rocks, Geologija 53(2): 182-196.

Runesson, K. 1987. Implicit integration of elastoplastic relations with reference to soils, International Journal for Numerical and Analytical Methods in Geomechanics 11(3): 315-321. http://dx.doi.org/10.1002/nag.1610110308

Sadrnejad, A. H. 2004. Introductory to plasticity theory in soil. Tehran: K.N.T.U. University. 248 p.

Serrano, A.; Olalla, C.; Manzanas, J. 2005. Stability of highly fractured infinite rock slopes with nonlinear failure criteria and nonassociated flow laws, Canadian Geotechnical Journal 42(2): 393-411. http://dx.doi.org/10.1139/t04-087

Sharan, S. K. 2005. Exact and approximate solutions for displacements around circular openings in elastic-brittle-plastic Hoek-Brown rock, International Journal of Rock Mechanics and Mining Sciences 42(4): 542-549. http://dx.doi.org/10.1016/j.ijrmms.2005.03.019

Siriwardane, H. J.; Desai, C. S. 1983. Computational procedures for non-linear three-dimensional analysis with some advanced constitutive laws, International Journal for Numerical and Analytical Methods in Geomechanics 7(2): 143171. http://dx.doi.org/10.1002/nag.1610070203

Wan, R. G. 1992. Implicit integration algorithm for HoekBrown elastic-plastic model, Computers and Geotechnics 14(3): 149-177.

http://dx.doi.org/10.1016/0266-352X(92)90031-N

Zergua, A.; Naimi, M. 2006. Elastic-plastic fracture analysis of structural columns, Journal of Civil Engineering and Management 12(2): 181-186.

Hadi HASANZADEHSHOOIILI. PhD Student of Dept of Civil Engineering, Faculty of Engineering, University of Guilan, Rasht, Guilan, Iran. He obtained his BSc in Mining Engineering from Urmia University in 2008; and his MSc in Geotechnical Engineering from University of Zanjan in 2011. His research interests include rock mechanics and geomechanics, geotechnical engineering, computational plasticity and mechanics, Hoek-Brown plasticity, numerical modeling, constitutive modeling of geo-materials and using ANNs in prediction of civil engineering's complicated problems.

Ali LAKIROUHANI. PhD Assist. Prof. of Dept of Civil Engineering, University of Zanjan, Zanjan, Iran. A graduate of Civil Engineering Faculty of Amirkabir University of Technology, Tehran, Iran (1998), MSc in geotechnical engineering (2000) and $\mathrm{PhD}$ in geotechnical engineering (2008). Research interests: hydraulic fracturing modeling (initiation of hydraulic fractures at a borehole to improve the interpretation of the in-situ stress from a hydraulic fracturing stress test.), tunneling, rock slope stability.

Jurgis MEDZVIECKAS. Dr, Assoc. Prof. of the Geotechnical Department of Vilnius Gediminas Technical University. A graduate of Civil Engineering Faculty of Vilnius Civil Engineering Institute (now - Vilnius Gediminas Technical University), Lithuania (1978). Dr in Structural Engineering (1989). Fields of research: foundation underpinning, relationship between ground and structures, estimation of soil mechanical properties. 